DEVELOPING GELATINE PLATES. By W. Bover.

Mr enthusiasm in photographic research having lost the sanguine impulse of youthful ardor, I am humbly content plates as a modestly slight modification of the generally adopted method, inasmuch as I discard the use of bromide,
and regulate the amount of pyrogallic to suit exposure and the quality of the gelitine plate. As is, unfortunately, frequently the case, gelatine plates lack uniformity.
With plates that are prone to over-intensity, I reduce With plates that are prone to over-intensity, I reduce
For thinily.coated plates I use grain to an ounce of water.
tix grains of pyrogallic to an ounce of water. 'To reduce the matter to rule bowever, I will imagine the plate perfect in all respects;

Pyrogallic

about 2 grains

Exposure-About one-tenth the time required for an ordinary wet collodion plate. Af ter exposure, place the plate in
a dish larger than the plate. For a $71 / 2$ by $41 / 2$ inch plate, I use a 10 by 8 glass bottom dish or tray. Flood the plate
with the pyrogallic solution, then tilt the dish to collect the pared as follows, must now be added:

Ammonia fort

2 diachms.

The highest lights will shortly apear; thes must be mitted to obtain some force before adding more ammonia to bring out the middle tones and details of shadows. The image should appear with exaggerated intensity as seen by
retlected light, but care must be taken that in this state gradation of strength is duly preserved. A few trials would
suffice to enable the operator to control the developmient. Keep the pyrogallic in excess, and guide with gradual additions of ammonia, which in weak solution can be used
without fear that a drop or two more or less can do much

I intensify weak images, when surh chance to turn up,
with B. J. Edwards's excellent formula, to which I add quite half more of hyposulphite than he recommends. This ad. dition makes the intensification controllable. and the color it
yields resembles that produced by the less reliable pyrogallic re-developer.
I bave given the plan as above stated to several of my its simplicity and comparative certainty in correcting varied exposures. In the hope that my readers might benefit from
the information also, I gladly add my mite to the fund which has been coutributed to so liberally by admirers of gelatine dry plates.

In conclusion I will briefly describe a mode of preparing a non-actinic medium which has cheapness and thorough
reliability to recommend it for general use-stout orangereliability to recommend it for general use-stout orange-
colored paper, sold at one penny per sheet, brushed over
one side with a liberal coating of aurine, then dried. Mix sweet oil with paraffin, in equal proportion. Rub this well
into the paper with a piece of flinnel, and you have a semiinto the paper with a piece of flinnel, and you have a semi-
transparent medium, by which dry gelatine or wet plates transparent medium, by which dry gelatine or wet p
may be developed with safety. - Photographic Nevos.

SIEMENS-MARTIN STEEL.

By Serator Kern, M.E., St. Petersburg.

THE chief steel works in Russia are situated near St.
Petersburg. The Obouchoff Steel Works have erected lately two 10-ton Siemens-Martin furnaces. The furnaces have no muffles for beating previously the charges introduced into from the Terre-Noire method, as described by Mr. A. L.
Holley. The author desires to give a short description of the modus operandi and a full account of some charges. The
charge consists of steel scrap, ladle scrap, and nanganese charge consists of steel scrap, ladle scrap, and nanganese
pig iron. A pig containing 9 to 12 per cent. of manganese
is ordinarily used. It is well known that big cast-steel inis ordinarily used. It is well known that big cast-steel in-
gots have a piping in their top part; and as such a part is of no use for forgings, therefore a certain part of the ingot,
when forged into the required shape, is always cut off under the steam bammer. Such ends are also used for the Siemens. Mirtin furnace. Very often ends weighing about 2 to $21 / 4$
tons are introduced among other steel scrap in the cold state into the furnace.
During the process of charging the furnace is kept as hot as possible. All the required materials, vic., pig iron, steel scrap, and ladle scrap (about 8 tons altogether) are charged at once, and no additional charges are introduced after the
metal is in a melted state, save if the testing of a sample out of the furnace shows that the metal is too hard; then, ordi-
narily, some 15 to $20 \mathrm{cwt}$. of good puddled iron blooms are
introduced into the metallic bath. The blooms are left for some time on the banks of the furnace doors, and when well
heated are thrown down into the metallic bath. But it bas beated are thrown down into the metallic bath. But it has
been found to be cheaper and quicker, in order to sof ten the been found to be cheaper and quicker, in order to soften the
metal, to introduce some 2 to $5 \mathrm{cwt}$. of good magnetic iron ore in the form of a fine powder. The steel tests taken
afterward soon show that the steel has turned mild; but if it happens that even then the steel is not so soft as desired.
another charge of 3 to $4 \mathrm{cwt}$. of magnetic ore with $1 \mathrm{cwt}$. of terro-manganese quickly brings the steel to the desired softness. Certainls, much depends on the state of the gas and
on the quality of the materials, but with a well-going furnace and good materials the above holds good.
Before the casting, if soft steel is wanled, $1 / 2$ to $1 \mathrm{cwt}$. of ferro-manganese is added, and for harder steel, containing
0.53 to 0.65 per cent. of carbon, of ten 3 to $10 \mathrm{cwt}$. of spiegeleisen is the additional charge. As there is no handy direct process to ascertain the amount of carbon in the samples taken out of the furnace, the engineer is of ten in a difficulty
in calculating the amount of the last charge of ferro-man ganese or spiegeleisen to be introduced into the metallic
bath. A very good test is the following: The sound part of a samp'e is leated to light welding heat, and hammered to the following dimensions (approximative): 5 (") $\times 0.5^{\prime \prime} \times \times^{5}$
This small bar, cooled slowly in ashes or sand, must bend
nearly double, and if it stands the test tolerably well, it may
be supposed to contain not more than 0.25 to 0.30 per cent. be supposed to contain not more than $0 \cdot 25$ to 0.30 per cent.
of carbon. The sample after being drawn, by hammering to a red heat.
The following charges give an idea of the mode of work ing.

Hard Steel.-Charge: Steel scrap, $120 \mathrm{cwt}$; ; ladle scrap. $17 \mathrm{cwt}$.; pig iron, containing 12 per cent. of manganese, 17
cwt.; all charged at once; charging commenced $4: 30 \mathrm{~A} . \mathrm{M}$.,
finished $6 \mathrm{~A} . \mathrm{M}$. Melted and one sampletaken out $8: 15 \mathrm{~A} . \mathrm{M}$.

\begin{tabular}{|l|l}
$17 \mathrm{cwt}$. puddled iron blooms charged 9 A.M.; sample ham- & either nickel free from cobalt is obtained in solution or \\
mered well, cooled, bent double; 15 cwt. pig iron, contain- & cobalt free from nickel as a precipitate. The required quan
\end{tabular} ing 9 per cent. of manganese, cliarged 10:20 A.M.; casting tity of sodium acetate may be calculated from the relative and place at $11 \mathrm{~A}$.M. Analysis of the steel: caibon, $0 \cdot 67$;
angese, 0.40 per cent.

Medium steel. - Clarge: Steel scrap, 135 cwt. : ladle scrap
3 cwt.; pig iron, containing 12 per cent. of manganese, 10
cwt.; charging commenced 1 P. M., finished $2: 45$ P.M. melled, $0 \cdot 5$ cwi. ferro-manganese added, and first test taken
$7: 40$ P.M. The steel was hard; $2 \cdot 5$ cwt. of magnetic iro ore added 7:55 P.M.; test taken 8:30 P.M.; sample bar
bent nearly double, given only a slight crack; 0.5 cwt. of

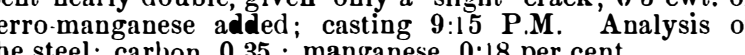
Soft Steel.-Charge: Steel sanese, 0.18 per cent.

Soft Steel.-Charge: Steel scrap, $113 \mathrm{cwt}$.; ladle scrap, 20
wt.; pig iron, containing 12 per cent. of manganese, 6 . cwt.; charging commenced 11 A.M.; finished $12: 30$ P.M.
Melted and first test, 6 P.M.; $2 \mathrm{cwt}$. ferro-manganese added 6:30 P.M.; test bar bent double after being bardened; ; cwt.
inro-manganese added 7 P.M.; casting, 7:15 P.M. Analy. ferro-manganese added 7 P.M.; casting, 7:15 P.M. Analy
sis of the steel: carbon, 0.16 ; manganese 0.14 per cent. ON steel was prepared for boiler plates.-Chemical Ners.
$=$
ON THE ELECTROLYTIC DETERMINATION
OF METAS. By LUDWIG ScHichi.

THE author's researches refer to the metals of the group The
molybdenum, selenium, and tellurium. Uranium is not prepitated from its solutions in mineral acids, but by the
intention condary action the effect of the nascent hydrogen uranic
xide is reduced to uranous oxide. From neutral solutions
is separated in very small quantities, of a yellow color. it is separated in very small quantities, of a yellow color.
Alkaline solutions containing organic acids (tartaric, citric, cetic), or mixed with sugar..deposit likewise very small

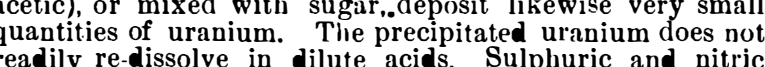
reations of thallium were prepared from the pure metal.
The aciduated solutions were not precipitated liy the curThe acidulated solutions were not precipitated hy the curdeposited at the cathode with a brisk disengagement of gas, whilst at the positive pole there appeared blackish brown
thallium oxide, much resembling lead peroxide. For the decomposition the author used at tirst the current from 4
Meidinger Pincus elements, riving hourly 160 c.c. of detonating gas, but this was fornt too strong, as the thallium
was deposited in a spongy stite and of a darker color. On using two or three elements fine, permanently adhesive meta
was obtained. From neutral solutions the metal is imper In alkaline solutions the separation is complete, and the
metal is bright and solid. It re-dissolves readily in sulplulur
ic acid. The oxide dissolves in hydrochloric acid, evolving ic acid. The oxide dissolves in bydrochloric acid, evolving Indium is completely precipitated as metal at the
negative pole, both from acid and alkaline solutions; in the negative pole, both from acid and alkaline solu
latter case the metal is very bright and firm.

Vanadium.-Vanadium chloride was dissolved in wate containing hydrochloric acid and electrolyzed. No precipimerely reduced to oxide. Sulphurous acid, organic acids,
mang and reduction occurs in the alkaline solution.

Palladium. - The nitrate, dissolved in water ancl acidified
vith a little nitric acid, deposited at the negative pole wronze-colored coating, which on continued action of the current became darker, and fnally black. It re-dissolve he positive pole. Alkaline solutions of palladium behave
n a similar manner, but the deposition is slower and more Molybdenum is precipitated from the ammoniacal solu-
on of molybdic acid as molybdous oxide, which appears at tion of molybdic acid as molybdous oxide, which appears at
the negative pole at first in colored rings, which gradually
thicken and become blue-black. The first blue precipitation
is molybdic molybdate; then follows molybdic oxide and molybdous oxide. The precipitation is complete and add
heres very firmly. In 'acid solutions there is uo precipita. heres very firmly. In 'acid solutions there is uo precipita
ion; in ammonium molvbdate acidified with free molybdic Selenium is readily and completely reduced and thrown
. should not be strong (two elements) or the deposit is purveru. xidized by boiling with nitric acid, and the solution of
ent. In order to determing metal is added, which occasions the separation of the selenior this purpose.
Tellurinm behaves like selenium, but it is reduced much more readily. From an acid solution it is easily deposited
with a blue-black color. Fron alkaline solutions it is thrown down in a very loose state at the positive pole, with strong
disengagement of gas. If much metal is present it floats on the surface of the liquid.
Gallium, like zinc, is th

Gallim, ofe zinc, is thrown down completely at the neg

WITH THE SALTS OF THE HEAVY METALS.* By H. DelfFs.

THE author called attention to the different precipitability the one band, and of acetic acid on the other. Just as the
the limit between precipitable and non-precipitable salts is alit is further modified if formiates are treated with sulphureted hydrogen. In that case the salt of zinc is precipitated, but the compounds of cobalt, nickel, iron, and manganese
are not affected. Manganese cannot be precipitated by sulManganese cannot be precipitated by sul-
phureted locted. metals are never simultaneously converted into the corre-
sponding sulphides, but the precipitation ensues in such a ponding sulphides, but the precipitation ensues in such
manner that one metal is first completely separated before the removal of another begins. Upon this fact is founded a state of purity. As sulphureted hydrogen first completely
precipitates cobalt acetate, and then acts upon nickel aceprecipitates cobalt acetate, and then acts upon nickel ace
tate, a solution of the two nitrates is mixed with sodium acetate in quantity insufficient for complete double decomccording to the respective proportions of the two metals, *A Aaper read before the Chemical Section of the Conpress of German
Naturalists and Physicians, at Baden-Baden, Sept. 19, 1879. quantities of the two metals which are mostly known. The a mixture of its salts with those of other metals, and thus a series of "chemical tension" may be established which, on always of the electromotoric actiou of the liquids, does not DETERMINATION OF ZINC. By W. AlEXandrowicz.

THE separation of zinc from the metals of the copper and The iron group presents considerable difficulties. The quan-
ity of zinc thrown down along with copper by sulphureted

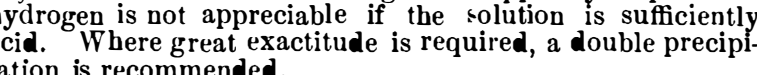
Thion is recommended.

The complete separation of cadmium and zinc by means
of sulphureted lydrogen is impossible, especially in presence of copper. In separating arsenic from zinc, if the solution 列 eted hydrogen.
In separating iron and zinc the author recommends that the solution of the mixed metals should be poured drop by
drop into the ammonia, and not rice rersa. The zinc re drop into the ammonia, and not vice rersa. The zinc re
mains in solution. The precipitate is then washed with am-

In separating manganese from zinc the author acidifes with acetic acid and precipitates with sulphureted lyydroged.
All the manganese remains in solution. $-R$, vue Univer welle
des Mines.

\section{METHYL CHLORIDE}

METHYL chloride, or the hydrochloric ether of metbylic
lcobol, is represented by the formula $\mathrm{C}_{2} \mathrm{H}_{3} \mathrm{Cl}=50.5$. It is aseous at common temperatures, possesses an ethereal odor
nd a saccharine taste; its specific gravity is 1.738 (air $=1.0$ at $0^{\circ}$ ). The weight of a liter of this gas $=2 \cdot 261$ grammes.
Water dissolves $2 \cdot 8$ vols. methyl chloride at $16^{\circ}$ and under a 40 , and absolute alcohol 35 vols. under the same conditions. Methyl chloride burns with a white flame edged with green, forming water, carbonic acid, and torrents of hydrochloric
acid gas. If nethyl chloride is compressed, it is e:sily con-
verted into a colorless and bighly mobile liquid boiling verted into a colorless and highly mobile liguid boiling
about $-23^{\circ}$ under the normal pressure of $0 \cdot 760 \mathrm{~m}$. The

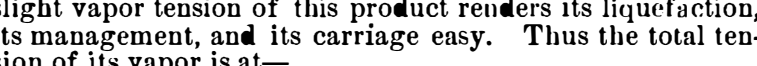

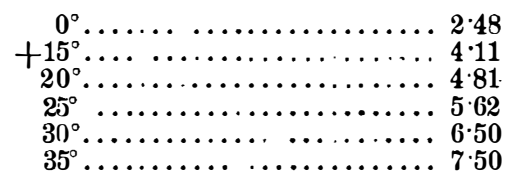

From these figures, one atmosphere must be deducted to fhe pressure really exercised upon the vessels contain Hitherto chloride of methyl, as prepared by the mutual
eaction of common salt, sulphuric acid, and methylic alcolol, has not been suitable for industrial applications on
account of the difficulty of preparing it in a state of purity t a moderate price. Quite recently M. Camille Vincen in abundance and free from impurities. This process consists in heating the hydrochlorate of tri-
nethylamine which is obtained industrially from the refuse of beet root. The hydrochlorate of tri-methylamine is thu decomposed into free trimethylamine, ammonia, and methy alkali, and the dried gas may then be liquefied by compres sion. The product thus obtained, perfectly pure. is manu-
factured on the large scale by MM. Brigonnet \& Son, a Saint Denis.
UsEs of METHYL CHLORIDE.

As a friproritic agent, methyl chloride may be employed
ither in the laboratory or in manufactures. If it is allowed to issue into an open vessel, it enters into a brisk ebullition orming a bath at $-23^{\circ}$, into which the objects to be refrig crated may be plunged. If the evaporation is intensified by
the injection of dry air, the temperature of the bath may be reduced to $-55^{\circ}$ in a few minutes, so as to freeze mercury. ory in which a bath of one liter of an incongealable liquid (e. $g$., alcohol) may be kept for some hours at a temperature M. Vincent has also double walls.

M. Vincent has also constructed a more complete apparaand so arranged that the methyl chloride may be recovered.
Large machines are also made adapted for cooling water air, etc., on the great scale. They bave the advantage of em-
ploying, as velicle of heat, a neutral liquid incapable of at ploying, as velicle of heat, a neutral liquid incapable of at unexplusive properties.
It must be remembered that the chloride of methyl can be used in any machine for the production of ice with the ex-
ception of those constructed to work with liquid ammonia.

\section{PREPARATION OF METHYLIC PRODUCTs.}

Methyl chloride is a product which offers great advan tages to the manufacturers of coloring matters derived from
coal-tar. It may serve in the manufacture of colored or colorable products in which methyl plays any part soever such as methylaniline, methyldiphenylamine, Dietliyltoluidio (which yields a red violet, Hofmann's violet, methyl-green, It is an advantageous substitute for the other methylic
(t) compounds commonly employed, such as methyl bromide,
iodide, and nitrate, the two former of which are costly and being a pure and anlydrous compound, is well adapted for quality of the product.

The methylated compounds which bave been already pre
pared with liquid methyl chloride are diamethylaniline pared with liquid methyl chloride are diamethylaniline We will briefly describe the preparation of the two latte To obtain green with methyl chloride, we place in an autoclave a solution of methylaniline violet in methylic
alcohol rendered basic by the addition of soda. The ap- 